\title{
Estado nutricional $x$ efetividade da hemodiálise: avaliação de pacientes atendidos em um serviço de Nefrologia da cidade de Pelotas-RS.
}

Matheus William de Morais da Silveira1; Pedro Henrique Barazzetti²; Carla Alberici Pastore ${ }^{3}$; Elizabeth Cristina Carpena Ramos ${ }^{4}$

\section{Resumo}

INTRODUÇÃO: A hemodiálise impacta no estado nutricional dos pacientes e a desnutrição traz prejuízos à qualidade de vida ao prognóstico. O Índice de Massa Corporal (IMC) é um método de avaliação nutricional fácil de executar e de baixo custo, porém limitado por não distinguir a composição corporal e por ser capaz de detectar apenas a desnutrição já instalada. O Primeiro Censo do Estado Nutricional de Pacientes em Hemodiálise no Brasil (2010), apontou 54,9\% dos pacientes eutróficos pelo IMC, porém 56,9\% destes apresentava Albumina sérica inferior a 3,5mg/dL.

Este estudo objetivou avaliar o estado nutricional de pacientes em hemodiálise e avaliar a efetividade do processo dialítico em relação ao estado nutricional.

MÉTODO: Estudo transversal com dados secundários dos prontuários dos pacientes em hemodiálise no serviço do Hospital de Beneficência Portuguesa de Pelotas no mês de Julho de 2015.

Foram coletados gênero, idade, altura e peso após a última sessão de diálise (para cálculo do IMC), e medidas séricas de Ureia pós-diálise e Creatinina, referentes ao início do mês de Julho/2015 para avaliação da

\footnotetext{
1 Graduando da Faculdade de Medicina da Universidade Federal de Pelotas, 5o semestre. Membro da Liga Acadêmica de Nefrologia - NefroVida. matheus07silveira@gmail.com

${ }^{2}$ Graduando da Faculdade de Medicina da Universidade Federal de Pelotas, 4ํㅗㄴ semestre. Membro da Liga Acadêmica de Nefrologia - NefroVida. Barazzetti_ph@hotmail.com

${ }^{3}$ Graduanda da Faculdade de Medicina da Universidade Federal de Pelotas, 6으 semestre. Membro da Liga Acadêmica de Nefrologia - NefroVida. pastorecarla@yahoo.com.br

${ }^{4}$ Professora do Departamento de Clínica Médica da Faculdade de Medicina da Universidade Federal de Pelotas. Orientadora da Liga Acadêmica de Nefrologia - NefroVida. eccarperamos@terra.com.br
} 
efetividade da diálise, e Albumina, referente ao primeiro semestre de 2015, para avaliação bioquímica do estado nutricional sérica (desnutrição=inferior a $3,5 \mathrm{mg} / \mathrm{dL}$ ).

Os dados, coletados por alunos da Liga Acadêmica de Nefrologia, foram digitados em planilha do software Microsoft Excel $2010^{\circledR} \mathrm{e}$ as análises estatísticas executadas com o Stata $11.1^{\circledR}$.

RESULTADOS: Foram avaliados 75 pacientes, $64 \%$ ( $\mathrm{n}=48$ ) do gênero masculino e a idade média da amostra foi $60,1 \pm 16,9$ anos, variando de 21 a 94 anos.

O IMC médio foi $25,1 \pm 4,4 \mathrm{Kg} / \mathrm{m}^{2}$, sendo que apenas $4,6 \%$ apresentou baixo peso, $47,7 \%$ era eutrófico e $47,7 \%$ apresentou excesso de peso. A Albumina sérica atingiu média de $3,7 \pm 0,6 \mathrm{mg} / \mathrm{dL}$ sendo que $24,0 \%$ apresentou taxa inferior a 3,5mg/dL. Demonstrando a baixa sensibilidade do IMC em diagnosticar a desnutrição, 32,3\% dos eutróficos e 18,2\% dos com peso excessivo apresentaram Albumina baixa.

Pacientes com níveis adequados de Albumina apresentam maiores níveis dos metabólitos nitrogenados quando comparados aos com Albumina baixa (ureia: $42,2 \pm 21,2 \times 26,5 \pm 15,6 \mathrm{mg} / \mathrm{dL}, \mathrm{p}=0,005$; creatinina: 7,97 $\pm 3,49$ $\mathrm{x} 5,84 \pm 2,16 \mathrm{mg} / \mathrm{dL}, \mathrm{p}=0,02-$ Teste $\mathrm{t}$ de Student).

CONCLUSÕES: Apesar das diferenças de sensibilidade entre os métodos para avaliação do estado nutricional, a desnutrição foi um achado importante. Sua abordagem e tratamento devem fazer parte do alvo terapêutico multiprofissional.

Palavras Chave: hemodiálise; desnutrição; albumina

\section{Referências}

GIBSON, R.S. Nutritional assessment: A laboratory manual. Oxford: Oxford University Press. 1993.

KAYSEN, G.A.; DUBIN, J.A.; MÜLLER, H.G.; ROSALES, L.M.; LEVIN, N.W. The acute-phase response varies with time and predicts serum albumin levels in hemodialysis patients. Kidney International, Saint Louis, v.58, n1., p.346-352, 2000. 
LOWRIE, E.G.; LEW, N.L. Death risk in hemodialysis patients: The predictive value of commonly measured variables and an evaluation of death rate differences between facilities. American Journal of Kidney Diseases, Boston, v.15, n.5, p.458-482, 1990.

MARTINS, C.T.B. $1^{\circ}$ Censo do Estado Nutricional de Pacientes em Hemodiálise do Brasil. Sociedade Brasileira de Nefrologia, São Paulo, 2010.

MIKOLASEVIC, I.; ORLIC, L.; VIDRIH, S.; POJE, B.; BUBIC, I.; VUJICIC, B.; RACKI, S. Assessment of nutritional status in patients with chronic kidney disease on maintenance hemodialysis. Acta Medica Croatica, Zagreb, v.68, n.2, p.97-102, 2014.

OLIVEIRA, G.T.C.; ANDRADE, E.I.G.; ACURCIO, F.A.; CHERCHIGLIA, M.L.; CORREIA, M.I.T.D. Avaliação nutricional de pacientes submetidos à hemodiálise em centros de Belo Horizonte. Revista da Associação Médica Brasileira, São Paulo, v.58, n.2, p.240-247, 2012.

OMS - Organização Mundial da Saúde. Obesity. Preventing and managing the global epidemic: report of a WHO Consultation. Geneva, World Health Organization. Technical Report Series, 894. 1998.

RAMBOD, M.; BROSS, R.; ZITTERKOPH, J.; BENNER, D.; PITHIA, J.; COLMAN, S.; KOVESDY, C.P.; KOPPLE, J.D.; KALANTAR-ZADEH, K. Association of Malnutrition-Inflammation Score with quality of life and mortality in hemodialysis patients: a 5-year prospective cohort study. American Journal of Kidney Diseases, Boston, v.53, n.2, p.298-309, 2009.

SANTOS, N.S.J.; DRAIBE, S.A.; KAMIMURA, M.A.; CUPPARI, L. Albumina sérica como marcador nutricional de pacientes em hemodiálise. Revista de Nutrição, Campinas, v.17, n.3, p.339-349, 2004.

SOHRABI, Z.; EFTEKHARI, M.H.; ESKANDARI, M.H.; REZAEIANZADEH, A.; SAGHEB, M.M. Malnutrition-inflammation score and quality of life in hemodialysis patients: is there any correlation? Nephro-urology Monthly, Tehran, v.7, n.3, p.e27445, 2015. 